\title{
SUPPORT FOR POPULATION LEVEL TOBACCO CONTROL POLICIES IN HUNGARY
}

\author{
Edit Paulik', Ágnes Maróti-Nagy ${ }^{1}$, László Nagymajtényi1 ${ }^{1}$, Todd Rogers², Doug Easterling ${ }^{3}$ \\ ${ }^{1}$ Department of Public Health, Faculty of Medicine, University of Szeged, Szeged, Hungary \\ ${ }^{2}$ RTI International, San Francisco, California, USA \\ ${ }^{3}$ Wake Forest School of Medicine, Winston-Salem, North Carolina, USA
}

\section{SUMMARY}

Background: Smoking is the leading, preventable risk factor for premature death and disability in Hungary. The objective of this paper was to assess the social acceptability of and the predictors of holding favourable attitudes toward tobacco control policies among the Hungarian population.

Methods: A self-administered questionnaire-based study was carried out among individuals aged 16-70 years. Logistic regression analysis was used to assess whether support for the ten tobacco control policies varies as a function of age, sex, educational level, and smoking status.

Results: The majority of the respondents supported the studied tobacco control measures. Over 90 percent of the sample supported: fines for retailers selling tobacco products to minors $(92.3 \%)$, stricter enforcement of restrictions on selling tobacco products to minors $(90.5 \%)$, and a ban on smoking in health care institutions (91.4\%). The lowest levels of support were for bans on sponsorship by the tobacco industry (52.8\%) and price increases on tobacco products $(54.9 \%)$. For each measure, support was significantly lower among smokers than non-smokers. Age and education were significantly related to support for some but not all measures.

Conclusions: Strong majorities of Hungarians support the enactment and enforcement of a wide range of tobacco control measures, a fact that was acknowledged by Parliament's passage of the 2011 Anti-Smoking Law. Advocacy efforts to encourage the acceptance of tobacco control policies should focus not only on smokers, but also on younger and less educated non-smokers.

Key words: smoking, tobacco control, public policy

Address for correspondence: E. Paullik, Department of Public Health, Faculty of Medicine, University of Szeged, H-6720 Szeged, Dóm tér 10, Hungary. E-mail: paulik.edit@med.u-szeged.hu

\section{INTRODUCTION}

Hungary has one of the highest rates of smoking among European countries (1), and leads the world in the rate of male lung cancer deaths and in the rate of coronary heart disease in men and women under the age of 65 years (2). It is well established that taxes on tobacco, smoking bans, advertising restrictions, and other tobacco-control policies have a dramatic impact on smoking prevalence and health-related outcomes $(3,4)$. Beginning in the early 1990 s, the Hungarian government enacted a series of important tobacco control policy measures. The Labour Safety Act of 1993 stipulated that specific smoking areas must be designated in all workplaces, or other organizational measures taken to provide for elimination of the harmful effects of environmental tobacco smoke (5). The Act on Advertising in 1997 (amended in 2001, $2005,2008)$ banned direct and indirect advertising for tobacco products (6-8). The Anti-Smoking Law in 1999 made it illegal to sell tobacco products to anyone under 18 , banned smoking in public buildings and on public transport, and prescribed separate smoking areas in restaurants $(9,10)$.

In 2004, Hungary ratified the WHO Framework Convention on Tobacco Control (FCTC) and committed to implementing policies in support of FCTC such as prohibiting smoking in offices, public buildings, restaurants, bars, company vehicles, and even in playgrounds (11). Following up on this commitment, the Hungarian Parliament amended the 1999 Anti-Smoking Law in April 2011 to more strictly regulate smoking in public places. The new law, which takes full effect in 2012, bans smoking completely in restaurants, workplaces, health care institutions, and closed public places as well as in specific outdoor public places including bus stops and playgrounds (12).

In addition to these laws restricting tobacco use, the Hungarian government has also increased taxes as means of discouraging smoking. Tobacco excise taxes were enacted several times during the last decades (e.g., in 1998, 2003, 2004 and 2006). Despite these tax increases, Hungary continues to maintain comparatively low prices for tobacco products in relation to average income $(13,14)$.

Tobacco control policy in Hungary has been enacted not only at the national level. More progressive "settlements" (generally mid-sized and larger cities) were out in front of the national government with regard to banning smoking in restaurants, public spaces, and playgrounds. And even with the passage of the 2011 amendments to the Anti-Smoking Law, some municipalities continue to have stronger regulations than mandated by the national government (10).

This study assesses Hungarians' attitudes toward a wide range of tobacco control policies (e.g., bans on smoking in closed public places, bans on tobacco advertising, fines for selling tobacco to 
minors, tax increases). A nationally representative sample of 2,250 Hungarian adults was interviewed between April and August of 2009 , two years prior to the passage of the new legislation. Acceptance is estimated for each of 10 tobacco control measures and is calculated separately for smokers and non-smokers. We also examine how acceptance varies as a function of age, gender, and educational level. These data provide an indication of how fully the new provisions will be accepted by the general public as well as showing whether there is support for additional tobacco control, particularly tax increases in Hungary.

This study provides the most detailed and reliable assessment of Hungarians' attitudes toward tobacco control currently available. In particular, the study expands on the findings from the most recent Eurobarometer study of tobacco conducted in December 2008 (1). That study showed that $86.7 \%$ of Hungarians support a ban on smoking in indoor workplaces, $81.1 \%$ support a ban on smoking in restaurants, and $61.9 \%$ support a ban on smoking in bars, pubs, and clubs. The current study improves on the Eurobarometer study in a number of ways. First, attitudes are elicited on a much wider range of tobacco control measures. Second, our sampling method (which selected households at random from a complete inventory) allowed for a more representative sample than was achieved with the Eurobarometer survey (which was based on random-digit-dial method among only landline phones). And third, our sample size $(n=2,250)$ is over twice as large as the Eurobarometer sample for Hungary $(\mathrm{n}=1,006)$.

\section{METHODS}

\section{Sampling and Participants}

Questionnaire data were collected in 2009 from adults in 48 settlements throughout Hungary. This was the first wave of a longitudinal study, with the second wave planned for 2012.

We used a two-stage sampling method. A nationally representative sample of 48 settlements (municipalities) from the seven geographical regions of Hungary was chosen in the first stage. In the second stage, a sample of individuals aged 16-70 years was selected randomly within each settlement based on the list provided by the Central Office for Administrative and Electronic Public Services of Hungary; one person from each identified household was chosen.

Of the 4,086 individuals selected for inclusion, researchers were able to make contact with 3,920 subjects. Of those contacted, 2,286 individuals completed the questionnaire, and 36 persons (questionnaires) were excluded because of the shortage of the basic demographic characteristics (age, sex, or education); data of the remaining 2,250 subjects were evaluated (response rate $=57.4 \%$ ).

\section{Study Variables}

Data collection was performed using a self-administered structured questionnaire to gather information on demographics, smoking behaviour, knowledge of and attitudes toward smoking and quitting, and attitudes toward tobacco control policies. Basic demographic characteristics included age, sex, and educational level. The level of education was categorized into three groups: low level (primary school), medium level (trade school, grammar school or vocational secondary school), and high level (college or university).

We classified each respondent's smoking status as current smoker, former smoker, or non-smoker. A current smoker was defined as someone who smoked daily or occasionally in the past 30 days. Former smokers were those who smoked in the past - at least 100 cigarettes in one's lifetime - but were not smoking for the preceding 30 days. Non-smokers were those who have never smoked or who smoked less than 100 cigarettes in their life (15).

To measure the attitudes toward tobacco control, we studied two groups of policies, the first aimed at limiting exposure to second-hand smoke (SHS) and the second aimed at regulating the availability of tobacco products. The specific policies included in the study correspond to the Framework Convention on Tobacco Control (FCTC) objectives and are consistent with key outcome indicators used to evaluate comprehensive tobacco control programmes $(11,16)$. In connection with the elimination of non-smokers' exposure to SHS, we asked participants about five measures: bans on smoking in closed public places; restrictions on smoking in outdoor public areas; bans on smoking in restaurants, cafeterias and pubs; restrictions on smoking in the workplace; bans on smoking in health care institutions. The next five measures were related to the marketing and availability of tobacco: increasing the price of tobacco products; bans on advertisement of tobacco products; bans on sponsoring of sport events, exhibitions, etc., by tobacco companies; fines for retailers selling tobacco products to minors; enforcing restrictions on selling tobacco products to minors. To assess attitude toward these policies, we adapted survey items used in large-scale tobacco control evaluation studies such as the California Adult Tobacco Survey (17). The level of agreement with each policy was evaluated as strongly agree, agree, disagree, strongly disagree, or uncertain. For the purposes of analyses, we dichotomized responses into supportive (strongly agree or agree) versus non-supportive (disagree, strongly disagree, uncertain) categories.

Internal consistency of key variables analysed in this paper was acceptable for both items assessing support for policies addressing SHS exposure (Cronbach alpha $=0.83$ ), and those addressing marketing and availability of tobacco products (Cronbach alpha $=0.74)$.

\section{Statistical Analyses}

Simple descriptive statistics were calculated to describe the basic characteristics of the sample. Logistic regression analyses were used to assess whether support for the 10 tobacco control policies varies as a function of age (as a continuous variable), sex, educational level, and smoking status. Analyses were conducted using the GENLIN procedure in SPSS version 17.0 for Windows. In order to adjust for geographic clustering within the sample (i.e., similarities among respondents who were from the same settlement), the analyses calculated robust standard errors for each of the predictors. We calculated the odds ratios (OR) and $95 \%$ confidence intervals $(95 \% \mathrm{CI})$ for each variable; and regarded $\mathrm{p}<0.05$ statistically significant. 
Table 1. Demographic and smoking characteristics of study population $(n=2,250)$

\begin{tabular}{|c|c|c|}
\hline Characteristics & $\mathrm{n}$ & $\%$ \\
\hline \multicolumn{3}{|l|}{ Sex } \\
\hline Male & 1053 & 46.8 \\
\hline Female & 1197 & 53.2 \\
\hline \multicolumn{3}{|l|}{ Age group, years } \\
\hline $16-24$ & 314 & 14.0 \\
\hline $25-44$ & 921 & 40.9 \\
\hline $45-64$ & 862 & 38.3 \\
\hline$\geq 65$ & 153 & 6.8 \\
\hline \multicolumn{3}{|l|}{ Educational level } \\
\hline Low & 418 & 18.6 \\
\hline Medium & 1390 & 61.8 \\
\hline High & 442 & 19.6 \\
\hline \multicolumn{3}{|l|}{ Smoking status } \\
\hline Current smoker & 748 & 33.2 \\
\hline Former smoker & 397 & 17.6 \\
\hline Non-smoker & 1105 & 49.1 \\
\hline
\end{tabular}

\section{RESULTS}

\section{Characteristics of the Sample}

Table 1 shows the characteristics of the study population. Gender distribution of the sample represented the Hungarian adult population. The mean age was $42.43 \pm 14.57$ years (min: $16 \mathrm{yrs}$; max: 70 yrs). Regarding the educational level, a higher proportion of the sample population was in the medium level group, while the proportion of those in the low and high educational level groups was nearly the same. Smoking prevalence was $33.2 \%(38.7 \%$ in males and $28.4 \%$ in females); $28.8 \%$ were daily smokers and $4.4 \%$ smoked occasionally.

\section{Support for Tobacco Control Policies}

Each of the 10 tobacco control measures studied here was supported by a majority of respondents (Fig. 1). Over 90 percent of the sample supported fines for retailers selling tobacco products to minors $(92.3 \%)$; stricter enforcement of restrictions on selling to minors $(90.5 \%)$; and a ban on smoking in health care institutions (91.4\%). Approximately 80 percent of the sample supported each of the other four measures involving restrictions on smoking (in closed public places, outdoor public areas, work places, restaurants, cafeterias, and pubs). A ban on advertising was supported by three-quarters of the sample. The two measures with the lowest levels of support were bans on sponsorship by the tobacco industry $(52.8 \%)$ and price increases on tobacco products $(54.9 \%)$.

For each tobacco control measure, support was significantly lower among smokers than among non-smokers ( $\mathrm{p}<0.001)$, with former smokers showing intermediate levels of support (Fig. 2). Despite this difference, it is important to note that 8 of the

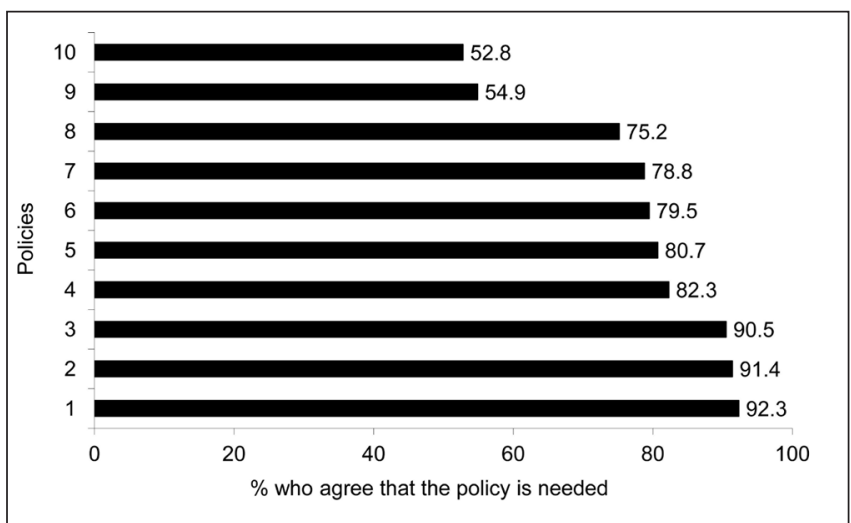

Fig. 1. Support for tobacco control policies - overall.

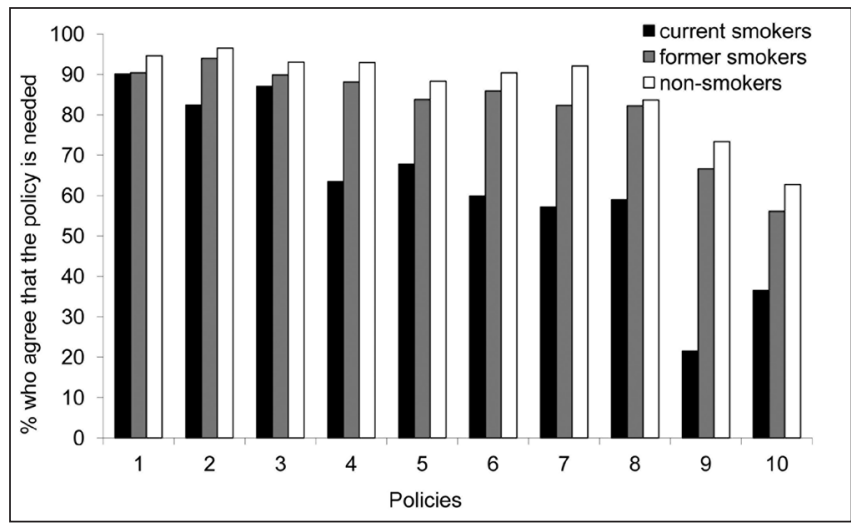

Fig. 2. Support for tobacco control policies by smoking status.

Legend to Fig. 1 and 2

1 - Fines for retailers selling tobacco products to minors

2 - Bans on smoking in health care institutions

3 - Enforcing restrictions on selling tobacco products to minors

4 - Bans on smoking in closed public places

5 - Restrictions on smoking in outdoor public areas

6 - Restrictions on smoking in work places

7 - Bans on smoking in restaurants, cafeterias, and pubs

8 - Bans on advertising tobacco products

9 - Increasing the prices of tobacco products

10 - Bans on sponsoring by tobacco industry

10 measures were supported by a majority of smokers - all but increasing the price of tobacco products (supported by $21.5 \%$ of current smokers) and bans on sponsorship (supported by $36.5 \%$ of current smokers).

In addition to smoking status, we tested whether support for the 10 measures varied as a function of age, gender, and educational level. The results are shown in Table 2 and 3. The strongest effect was found for educational level. Respondents with more than 12 years of education ("high") consistently showed the greatest levels of support, while those with 8 or less than 8 years ("low") were least supportive. Women were generally more supportive than men, with the difference attaining statistical significance for 4 of the 10 measures. The greatest gender differences occurred for restricting smoking in the work place $(\mathrm{OR}=1.54, \mathrm{p}<0.01)$. Older respondents were generally more supportive of the measures than were younger respondents. The effect of age was significant for 6 of the 10 measures. 
Table 2. The agreement with the measures on the elimination of non-smokers exposure to second-hand smoke - logistic regression analysis

\begin{tabular}{|c|c|c|c|c|c|}
\hline & $\begin{array}{l}\text { Bans on smoking } \\
\text { in closed public } \\
\text { places }\end{array}$ & $\begin{array}{l}\text { Restrictions on } \\
\text { smoking in outdoor } \\
\text { public areas }\end{array}$ & $\begin{array}{l}\text { Bans on smoking } \\
\text { in restaurants, } \\
\text { cafeterias, and pubs }\end{array}$ & $\begin{array}{l}\text { Restrictions on } \\
\text { smoking in work } \\
\text { places }\end{array}$ & $\begin{array}{l}\text { Bans on smoking } \\
\text { in health care } \\
\text { institutions }\end{array}$ \\
\hline & OR $(95 \% \mathrm{Cl})$ & OR $(95 \% \mathrm{Cl})$ & OR $(95 \% \mathrm{Cl})$ & OR $(95 \% \mathrm{Cl})$ & OR $(95 \% \mathrm{Cl})$ \\
\hline Age & $1.02(1.01 ; 1.03)^{\star \star \star}$ & $1.00(0.99 ; 1.01)$ & $1.01(1.01 ; 1.02)^{\star *}$ & $1.02(1.01 ; 1.03)^{* * *}$ & $1.00(0.99 ; 1.01)$ \\
\hline \multicolumn{6}{|l|}{ Sex } \\
\hline Males & 1.00 & 1.00 & 1.00 & 1.00 & 1.00 \\
\hline Females & $1.06(0.81 ; 1.37)$ & $1.30(1.01 ; 1.67)^{*}$ & $1.36(1.03 ; 1.79)^{*}$ & $1.54(1.20 ; 1.99)^{\star *}$ & $1.08(0.81 ; 1.45)$ \\
\hline \multicolumn{6}{|l|}{ Educational level } \\
\hline Low & 1.00 & 1.00 & 1.00 & 1.00 & 1.00 \\
\hline Medium & $1.44(1.05 ; 1.96)^{*}$ & $1.21(0.89 ; 1.66)$ & $1.34(0.98 ; 1.82)$ & $1.19(0.87 ; 1.62)$ & $1.47(0.99 ; 2.19)$ \\
\hline High & $1.67(1.03 ; 2.72)^{*}$ & $1.20(0.84 ; 1.71)$ & $1.69(1.13 ; 2.54)^{\star *}$ & $1.75(1.18 ; 2.59)^{* *}$ & $1.44(0.80 ; 2.59)$ \\
\hline \multicolumn{6}{|l|}{ Smoking status } \\
\hline Current smoker & 1.00 & 1.00 & 1.00 & 1.00 & 1.00 \\
\hline Former smoker & $3.61(2.37 ; 5.48)^{\star * *}$ & $2.35(1.69 ; 3.28)^{\star \star *}$ & $3.09(2.12 ; 4.49)^{* * *}$ & $3.46(2.54 ; 4.71)^{* * *}$ & $3.17(2.08 ; 4.83)^{* * *}$ \\
\hline Non-smoker & $7.55(5.60 ; 10.17)^{\star \star *}$ & $3.45(2.50 ; 4.77)^{\star \star *}$ & $8.30(5.83 ; 11.83)^{\star * *}$ & $5.99(4.34 ; 8.27)^{* * *}$ & $5.91(3.90 ; 8.94)^{* * *}$ \\
\hline
\end{tabular}

OR odds ratio, $\mathrm{Cl}$ confidence interval; ${ }^{*} \mathrm{p}<0.05 ;{ }^{* *} \mathrm{p}<0.01 ;{ }^{* * *} \mathrm{p}<0.001$

\section{DISCUSSION}

In this study, we evaluated the social acceptability of ten tobacco control policies and demonstrated that the majority of Hungarians are supportive of all of these policies. Support was particularly high for the provisions included in the 2011 AntiSmoking Law, including bans on smoking in closed and outdoor public places, restaurants, cafeterias, pubs or health care institutions as well as restrictions on smoking in the workplace. Even stronger support was observed for fines on retailers who sell tobacco products to minors. Much lower levels of support were found for increasing the price of tobacco products and banning sponsoring of various events by the tobacco industry. Not surprisingly smokers were less supportive of these measures than were non-smokers, however, a strong majority of smokers backed bans on selling tobacco to minors and more than half supported each of the proposed bans on smoking. In addition to smoking status, acceptance varied as a function of age and educational level, but not gender. Policies were less supported among younger respondents and among people with lower educational attainment.

The Flash Eurobarometer on Tobacco conducted in 2008 (1) found that the majority of EU citizens support smoke-free public places, such as offices and other indoor work places $(73 \%$ are totally in favour and $11 \%$ marginally in favour). The same level of support was found for such restrictions in restaurants $(63 \%$ are totally in favour and $16 \%$ marginally in favour). These findings are in agreement with the results of our study: most of our interviewees $(79.5 \%$ and $78.8 \%)$ supported the above mentioned regulations.

A study conducted in Switzerland found similar results to our study with regard to attitudes toward selling of tobacco to minors (18). In our study, $92.3 \%$ of the Hungarian sample favoured fines for retailers who sell tobacco to minors, compared to $92.2 \%$ among the Swiss sample. Likewise, a total ban of tobacco ad- vertising was also supported by $75.2 \%$ of our sample compared to $77.7 \%$ of the Swiss sample.

We found that subjects with higher educational level favoured stronger measures than the lower educated; these results are consistent with the literature $(19,20)$, except for the unexpected results in Switzerland, where researchers have revealed a higher support for smoking policies by the lower educated subjects (18).

In several studies, smoking status has been defined as the main predictor of attitudes toward tobacco control: low support was found among smokers (18-22). Our study found the same trend.

This survey provides a more in-depth and reliable assessment of Hungarians' attitudes toward tobacco control policy than is available through prior studies. According to our results, antismoking policies including prohibitive measures are accepted by a large part of the Hungarian population. The most supported measures are related to the protection of minors. Moreover, there is strong public sentiment in favour of stricter enforcement of these measures.

There are two other areas where additional policy change is appropriate in Hungary. Firstly, the government should impose additional excise taxes to bring the real price of tobacco more in line with other European countries. Second, the partial ban on sponsorship that is currently in place should be expanded to fall into line with the FCTC principles. Our data show that each of these two policy changes is supported by a small majority of non-smokers and opposed by the vast majority of smokers. Strategic advocacy efforts tailored to the Hungarian context will be required to bring about these policy changes.

In interpreting our results, it is important to keep in mind the study's limitations. Virtually all surveys conducted in recent years have been plagued with imperfect response rates. In our study $57.4 \%$ of the adults we approached agreed to participate. This figure is superior to what is typically achieved in random digit dial telephone surveys, but still allows the possibility of selection 
Table 3. The agreement with the measures on the marketing and availability of tobacco - logistic regression analysis

\begin{tabular}{|c|c|c|c|c|c|}
\hline & $\begin{array}{l}\text { Increasing the prices } \\
\text { of tobacco products }\end{array}$ & $\begin{array}{l}\text { Bans on advertising } \\
\text { tobacco products }\end{array}$ & $\begin{array}{l}\text { Bans on sponsoring } \\
\text { by tobacco industry }\end{array}$ & $\begin{array}{l}\text { Fines for retailers } \\
\text { selling tobacco } \\
\text { products to minors }\end{array}$ & $\begin{array}{c}\text { Enforcing restrictions } \\
\text { on selling tobacco } \\
\text { products to minors }\end{array}$ \\
\hline & OR $(95 \% \mathrm{Cl})$ & OR $(95 \% \mathrm{Cl})$ & OR $(95 \% \mathrm{Cl})$ & OR $(95 \% \mathrm{Cl})$ & OR $(95 \% \mathrm{Cl})$ \\
\hline Age & $1.01(1.00 ; 101)^{*}$ & $1.02(1.01 ; 1.03)^{* * *}$ & $1.01(1.00 ; 1.01)^{\star}$ & $1.01(0.99 ; 1.02)$ & $1.00(0.99 ; 1.01)$ \\
\hline \multicolumn{6}{|l|}{ Sex } \\
\hline Males & 1.00 & 1.00 & 1.00 & 1.00 & 1.00 \\
\hline Females & $1.02(0.87 ; 1.19)$ & $1.22(1.01 ; 1.46)^{*}$ & $1.05(0.90 ; 1.23)$ & $1.32(0.93 ; 1.88)$ & $1.23(0.98 ; 1.53)$ \\
\hline \multicolumn{6}{|l|}{ Educational level } \\
\hline Low & 1.00 & 1.00 & 1.00 & 1.00 & 1.00 \\
\hline Medium & $1.32(1.05 ; 1.65)^{\star}$ & $1.33(1.05 ; 1.69)^{*}$ & $1.06(0.86 ; 1.30)$ & $1.57(1.05 ; 2.34)^{*}$ & $1.94\left(1.35 ; 2.789^{* * *}\right.$ \\
\hline High & $1.52(1.14 ; 2.02)^{\star *}$ & $1.37(0.93 ; 2.01)$ & $1.23(0.96 ; 1.59)$ & $1.57(1.01 ; 2.43)^{*}$ & $1.95(1.25 ; 3.02)^{\star *}$ \\
\hline \multicolumn{6}{|l|}{ Smoking status } \\
\hline Current smoker & 1.00 & 1.00 & 1.00 & 1.00 & 1.00 \\
\hline Former smoker & $6.81(5.05 ; 9.17)^{\star \star *}$ & $2.71(1.82 ; 4.04)^{* * *}$ & $2.09(1.59 ; 2.76)^{\star \star \star}$ & $0.95(0.68 ; 1.32)$ & $1.22(0.85 ; 1.74)$ \\
\hline Non-smoker & $9.95(7.51 ; 13.19)^{\star * \star}$ & $3.54(2.60 ; 4.81)^{* \star *}$ & $2.86(2.17 ; 3.76)^{* \star *}$ & $1.83(1.29 ; 2.59)^{* * *}$ & $1.92(1.44 ; 2.55)^{* * *}$ \\
\hline
\end{tabular}

OR odds ratio, $\mathrm{Cl}$ confidence interval; ${ }^{*} \mathrm{p}<0.05 ;{ }^{* *} \mathrm{p}<0.01 ;{ }^{* * *} \mathrm{p}<0.001$

bias. We do not believe that this bias is large given the alignment between the demographic characteristics of our sample compared to the known characteristics of the adult population in Hungary.

Another potential source of bias in our study (as in all surveybased studies) is the self-report nature of the data. Compared to a telephone survey, our methodology (where researchers delivered the questionnaire and requested that the respondent mail it back) eliminated the need for respondents to disclose their behaviour and attitudes to an interviewer.

In sum, we believe that this study has far fewer limitations than any prior national survey of tobacco use and attitudes conducted in Hungary. Indeed, the ability to recruit participants through an official listing of all inhabitants of the country is an advantage that is unavailable to researchers in most countries.

\section{CONCLUSIONS}

Strong majorities of Hungarians support the enactment and enforcement of a wide range of tobacco control measures, a fact that was acknowledged by Parliament's passage of the 2011 AntiSmoking Law. Information on the predictors of tobacco control related attitudes might represent a useful tool for implementation tobacco control strategies more tailored to the population demands. Our results suggest that advocacy efforts to enforce the existing tobacco control policies should focus not only on smokers, but also younger and less educated residents. The implementation of effective tobacco control interventions would result in the fall of social acceptance and prevalence of smoking and, eventually, of smoking-related morbidity and mortality in Hungary.

\section{Acknowledgements:}

We would like to thank Dr. John S. Preisser (Research Professor, Department of Biostatistics, School of Public Health, The University of North
Carolina at Chapel Hill) for his contribution to the statistical analysis. The contribution of field workers and other study personnel is gratefully acknowledged.

\section{Statement on conflict of interest:}

None declared.

\section{Funding:}

This work was supported by the Fogarty International Centre, the National Cancer Institute, and the National Institutes on Drug Abuse, within the National Institutes of Health (Grant Number 1 R01 TW007927-01). Its contents are solely the responsibility of the authors and do not necessarily represent the official view of the National Institutes of Health.

\section{Ethical aspects:}

The study protocol was approved by the Regional and Institutional Human Medical Biological Research Ethics Committee of the University of Szeged (No. 2431/2008). Informed written consent was obtained from the study population, in case of young subjects (under 18 years) parental permission was sought to speak to them.

\section{REFERENCES}

1. The Gallup Organization. Survey on tobacco: analytical report [Internet]. 2009 Mar [cited 2009 Apr 13]. Available from: http://ec.europa.eu/public opinion/flash/fl 253 en.pdf.

2. O`Kelly S. EuroHeart 2009 [Internet]. 2009 Sep [cited 2010 Aug 22]. Available from: http:/www.eurekalert.org/pub releases/2009-09/esoce2090809.php

3. Thomas S, Fayter D, Misso K, Ogilvie D, Petticrew M, Sowden A, et al. Population tobacco control interventions and their effects on social inequalities in smoking: systematic review. Tob Control. 2008 Aug;17(4):230-7.

4. Cokkinides V, Bandi P, McMahon C, Jemal A, Glynn T, Ward E. Tobacco control in the United States - recent progress and opportunities. CA Cancer J Clin. 2009 Nov-Dec;59(6):352-65. 
5. Act XCIII of 1993 on workers protection [Internet]. [cited 2010 Oct 6]. Available from: http://net.jogtar.hu/jr/gen/hjegy_doc. cgi?docid=99300093.TV $/$. (In Hungarian.)

6. Act LXXVII of 2005 on advertising an amendment of Act LVIII of 1997 [Internet]. [cited $2011 \mathrm{Jul}$ 13]. Available from: http://www.complex.hu/ kzldat/t0500077.htm/t0500077.htm. (In Hungarian.)

7. Szilágyi T. Hungary introduces a total ban on tobacco advertising. Tob Control. 2002 Mar;11(1):79-81.

8. Act XLVIII of 2008 on advertising [Internet]. [cited 2011 Jul 13]. Available from: http://net.jogtar.hu/jr/gen/hjegy_doc.cgi?docid=A0800048. TV. (In Hungarian.)

9. Act XLII of 1999 on the protection of non-smokers and the regulation of tobacco sales, marketing and use [Internet]. [cited 2010 Oct 6]. Available from: http://net.jogtar.hu/jr/gen/hjegy_doc.cgi?docid=99900042.TV/. (In Hungarian.)

10. Lomnici Z, Fejér E, Gazsó BL, Rónyai N. Operative legislative provisions of organizations and the Hungarian tobacco control program. Hungarian policy and investigation. Egészségtudomány [Internet]. 2011 [cited 2011 Jul 11];55(2):99. Available from: http://egeszsegtudomany.higienikus.hu/ cikk/2011-2/2011-2.pdf. (In Hungarian.)

11. World Health Organization. WHO Framework Convention on Tobacco Control [Internet]. Geneva: WHO; 2003, updated reprint 2004, 2005 [cited 2010 Oct 10]. Available from: http://whqlibdoc.who.int/publications/2003/9241591013.pdf.

12. Act XLI of 2011 an amendment of Act XLII of 1999 on the protection of non-smokers and the regulation of tobacco sales, marketing and use [Internet]. [cited 2011 May 5]. Available from: http://www.kozlonyok. hu/nkonline/MKPDF/hiteles/MK11048.pdf. (In Hungarian.)

13. Szilágyi T. Increasing taxes of tobacco products and decreasing smoking: experiences and suggestions. Study for the Hungarian Coalition on Tobacco Control [Internet]. 2006 [cited 2011 Jul 13]. Available from: http://www.health21.hungary.globalink.org/koal_menu_elemei/dohanyado_vegso.doc. (In Hungarian.)
14. Act CXXVII of 2003 on excise tax and distribution of excise products [Internet]. [cited $2011 \mathrm{Jul}$ 13]. Available from: http://www.complex.hu/ $\mathrm{jr} / \mathrm{gen} / \mathrm{hjegy}$ doc.cgi?docid=A0300127.TV\&timeshift=0. (In Hungarian.)

15. World Health Organization. Monitoring tobacco use. In: Guidelines for controlling and monitoring the tobacco epidemic [Internet]. Geneva: WHO; 1998 [cited 2009 Jan 2]. Available from: http://health21.hungary. globalink.org/koal menu elemei/WHO.DOC. (In Hungarian.)

16. Starr G, Rogers T, Schooley M, Porter S, Wiesen E, Jamison N. Key outcome indicators for evaluating comprehensive tobacco control programs. Atlanta, GA: Centers for Disease Control and Prevention; 2005.

17. California Adult Tobacco Survey (CATS) Instrument. California adult tobacco survey: 2007 questionnaire [Internet]. Sacramento (CA): CATS; 2007 [cited 2009 Mar 4]. Available from: http://www.cdph.ca.gov/programs/tobacco/Documents/CTCP-CATSQuestionnaire2007.pdf.

18. Marques-Vidal P, Melich-Cerveira J, Paccaud F, Waeber G, Vollenweider $\mathrm{P}$, Cornuz J. Opinions on tobacco control policies in Lausanne, Switzerland, 2003-2006. Prev Med. 2010 Aug;51(2):193-4.

19. Schumann A, John U, Thyrian JR, Ulbricht S, Hapke U, Meyer C. Attitudes towards smoking policies and tobacco control measures in relation to smoking status and smoking behaviour. Eur J Public Health. 2006 Oct; 16(5):513-9.

20. Abdullah AS, Yang T, Beard J. Predictors of women's attitudes toward world health organization framework convention on tobacco control policies in urban China. J Womens Health (Larchmt). 2010 May;19(5):903-9.

21. Foley KL, Balázs P. Social will for tobacco control among the Hungarian public health workforce. Cent Eur J Public Health. 2010 Mar;18(1):25-30.

22. Thyrian JR, Panagiotakos DB, Polychronopulos E, Willemsen MC Zatoński W, John U. The exposure to environmental tobacco smoke and attitudes towards tobacco control measures - a comparison of 5 European countries. Cent Eur J Public Health. 2010 Jun;18(2):87-92.

Received August 29, 2011 Accepted in revised form November 11, 2011 